\title{
Política linguística exterior brasileira e política linguística francesa em contato: o caso do português como língua de herança (PLH) no dispositivo Intervenant en Langue Maternelle na Guiana Francesa
}

\author{
Karen Kênnia Couto Silva*
}

Resumo

O ensino do português como língua de herança (PLH) tem recebido, nos últimos anos, muita atenção dos pesquisadores. No âmbito político-institucional, o ensino do português para falantes de outras línguas também tem tido especial atenção dos tomadores de decisão no âmbito da política linguística, preocupados não somente com o desenvolvimento escolar do aluno, mas também focados no aspecto formativo integral desse aluno. Dentro desse contexto, podemos dizer que é nas regiões fronteiriças que essas dinâmicas se mostram presentes e ainda mais intensas, sendo comum que a população dessas regiões seja notadamente multilíngue e plurilíngue. Esse é o caso, em especial, da fronteira norte do Brasil, no estado do Amapá, com a Guiana Francesa, onde se registra o contato entre o português e o francês. Desse modo, o objetivo deste estudo é apresentar o dispositivo de política linguística Intervenant en Langue Maternelle (ILM), como uma possibilidade de ensino de PLH integrada ao sistema de ensino francês em favor de alunos que têm o português como língua materna (L1) ou língua de herança (LH). Após apresentarmos o dispositivo, iremos discutir como a Proposta curricular para o ensino de português como língua de herança (BRASIL, 2020b), do Ministério das Relações Exteriores, pode servir como um documento de referência

\footnotetext{
Doutora em Linguística A plicada pela Universidade Federal de Minas Gerais (UFMG). Doutora em Linguística pela Université de Guyane (UG). Atualmente é leitora de língua portuguesa na Université Sorbonne-Nouvelle selecionada por meio do Programa Leitorado, do Ministério das Relações Exteriores em parceria com a CAPES. ORCID: https://orcid.org/0000-00019925-1392.
} 
para subsidiar o trabalho dos professores nas classes de ILM. Por fim, teceremos considerações acerca do exposto no artigo, buscando sugerir pontos de observação e melhoria para o ensino-aprendizagem de PLH na Guiana Francesa com base nas propostas curriculares.

Palavras-chave: PLH. Política linguística. Didática do bi/ plurilinguismo. Bilinguismo. Guiana Francesa.

\section{La politique linguistique extérieure brésilienne et la politique linguistique française en contact: le cas du PLH dans le dispositif Intervenant en Langue Maternelle en Guyane}

\section{Résumé}

L'enseignement du portugais comme langue d'héritage (PLH) a reçu beaucoup d'attention ces dernières années de la part des chercheurs. Dans le domaine politique-institutionnel, l'enseignement du portugais aux locuteurs d'autres langues a également reçu une attention particulière de la part des décideurs dans le domaine de la politique linguistique, soucieux non seulement du développement scolaire de l'élève, mais aussi de l'aspect intégral de formation de cet étudiant. Dans ce contexte, nous pouvons dire que c'est dans les régions frontalières que ces dynamiques sont présentes et encore plus intenses, et qu'il est courant que la population de ces régions soit remarquablement multilingue et plurilingue. C'est notamment le cas de la frontière nord du Brésil, dans l'État d'Amapá avec la Guyane, où le contact entre le portugais et le français est enregistré. Ainsi, l'objectif de cette étude est de présenter le dispositif de politique linguistique Intervenant en Langue Maternelle (ILM), comme étant une possibilité d'enseignement du PLH intégré dans le système éducatif français en faveur des élèves ayant 
le portugais comme langue maternelle ou langue d'héritage (PLH). Après avoir présenté le dispositif, nous discuterons de la façon dont la Proposta curricular para o ensino de português como língua de herança (BRASIL, 2020b) du Ministère des Affaires étrangères du Brésil peut servir de référence pour aider le travail des enseignants dans les classes ILM. Enfin, nous ferons des réflexions sur ce qui a été exposé dans l'article, en cherchant à proposer des points d'observation et d'amélioration pour l'enseignement-apprentissage des PLH en Guyane à partir des propositions curriculaires.

Mots-clés: PLH. Politique linguistique. Didactique du bi/ plurilinguisme. Bilinguisme. Guyane.

Recebido em: 08/03/2021 // Aceito em: 20/04/2021. 


\section{Introdução}

O ensino do português como língua de herança (PLH) tem recebido, nos últimos anos, muita atenção dos pesquisadores. São inúmeros os congressos, simpósios, conferências relacionadas à temática, evidenciando o crescimento da importância da área no meio acadêmico. No âmbito político-institucional, vinculado às políticas linguísticas, o ensino de PLH também tem tido especial atenção dos tomadores de decisão no âmbito educacional, preocupados não somente com o desenvolvimento escolar do aluno, mas também com o seu aspecto formativo integral, em respeito às suas origens. Nesse sentido, o ensino bilíngue, ou mesmo plurilíngue, tem sido adotado por diferentes instituições ao redor do mundo para levar em conta essa nova realidade social em diferentes países.

De fato, o aluno ingressante em um sistema de ensino no exterior se vê confrontado com uma situação em que a língua de herança não coincide, na maior parte das vezes, com a língua de escolarização. De acordo com Boruchowsky,

após iniciar a imersão escolar na língua majoritária, observa-se uma tendência à diminuição do uso da língua de herança (Carreira \& Kagan, 2011). A língua da família, no caso o português variante brasileira, passa a ser menos utilizada pela criança e torna-se a "língua fraca" (BORUCHOWSKY, 2016, p. 12).

A autora evidencia ainda que essa perda linguística se acelera quando os pais acreditam que, falando a língua de escolarização ou a língua majoritária com seus filhos, ajudarão no bom desempenho deles na escola (BORUCHOWSKY, 2016). 
Política linguística exterior brasileira e política linguística francesa em contato: o caso do português como língua de herança (PLH) no dispositivo Intervenant en Langue Maternelle na Guiana Francesa

O ensino bilíngue representa, portanto, um duplo desafio no sistema de ensino. Por um lado, o aspecto simbólico da língua dos pais na formação da criança é algo que não pode ser negligenciado pela escola. Por outro, há a necessidade de integração dessa criança no ambiente sociocultural do país de residência com o desenvolvimento da língua de escolarização, sem que isso represente um prejuízo do patrimônio linguísticocultural, história e identidade do aluno. Se, antes, as políticas linguísticas oficiais eram refratárias ao ensino bi/plurilíngue, atualmente, o cenário tem sido diferente. A língua do aprendente é, muitas vezes, utilizada como um recurso nas políticas de acolhimento de alunos recém-chegados ao sistema de ensino, possibilitando-lhes uma melhor adaptação ao novo contexto de ensino-aprendizagem. Ademais, para além da integração no país, o ensino bilíngue é também uma questão relacionada a direitos linguísticos fundamentais, sendo cada vez mais demandado que países democráticos e compromissados com a proteção integral dos direitos humanos estejam sensíveis a essas novas dinâmicas transnacionais.

Dentro desse contexto, podemos dizer que é nas regiões fronteiriças que essas dinâmicas se mostram presentes e ainda mais intensas, sendo comum que a população dessas regiões seja notadamente multilíngue e plurilíngue. ${ }^{1}$ Esse é o caso, em especial, da fronteira norte do Brasil, no estado do Amapá, com a Guiana Francesa, onde se registra o contato entre o português e o francês. ${ }^{2}$ Devido à forte presença da comunidade brasileira

\footnotetext{
1 O Cadre Européen Commun de Référence (CECR), importante documento publicado pelo Conseil de l'Europe em 2001, define o multilinguismo como a coexistência ou conhecimento de diferentes línguas em uma dada sociedade, enquanto o plurilinguismo seria a competência comunicativa possuída pelo indivíduo em mais de um idioma.

2 Diversas outras línguas são faladas na Guiana Francesa: "além do crioulo guianense, de base lexical francesa, e línguas businenge, de base lexical inglesa, deve-se notar que o srnan tongo (a língua veicular do vizinho Suriname) e, em menor grau, o crioulo inglês da Guiana (ou crioulo da Guiana) também são praticados, especialmente na parte ocidental do departamento. Além disso, há pelo menos seis línguas indígenas. Finalmente, uma parcela significativa da população usa português (brasileiro), holandês, inglês, chinês e hmong na vida cotidiana, e espanhol ou russo também são falados” (FRANCE, 2020, p. 22).
} 
na região e, consequentemente, ao grande número de alunos que têm o português como língua de herança ${ }^{3}$ matriculados no sistema de ensino na Guiana Francesa, as autoridades educativas locais se viram frente ao desafio de escolarizar essas crianças. $\mathrm{Na}$ França, o termo língua de herança não é utilizado, sendo adotada a concepção de ensino de língua materna e língua de acolhimento. $\mathrm{O}$ ensino bilíngue para línguas e culturas regionais e minoritárias é respaldado pelo Code de l'éducation francês, mas, de forma facultativa e concomitante com a língua francesa. Nesse sentido, cabe a cada académie régionale definir as orientações de política educativa para o bilinguismo, conforme as suas especificidades locais.

Na Guiana Francesa, para assegurar o ensino do português, um dos meios encontrados foi incluí-lo em um dispositivo de política linguística local concebido originariamente para as línguas regionais e minoritárias da Guiana Francesa, denominado Intervenant en Langue Maternelle(ILM). O mérito dessa proposta é o de proporcionar o acolhimento ao aluno não francófono no interior do próprio sistema de ensino francês, permitindo que essas crianças desenvolvam as diferentes competências em língua materna ${ }^{4}$ (L1) ao mesmo tempo em que se busca valorizar as origens culturais desses alunos. No caso do português, a única langue vivante étrangère ${ }^{5}$ contemplada nesse dispositivo, o ILM tem cumprido um papel fundamental na adaptação das crianças brasileiras ao sistema de ensino francês, permitindo não somente a integração desses alunos, mas também lhes oferecendo a

\footnotetext{
3 No contexto guianense, é comum as línguas minoritárias coincidirem com a língua de herança ou a língua materna (L1) do aluno.

4 Em grande parte dos casos, o português é a língua "fraca" tanto para as crianças brasileiras recém-chegadas ao território guianense, quanto para aquelas que têm o português como língua de herança na Guiana Francesa. Muitas crianças falam o português sem serem necessariamente alfabetizadas nessa língua.

5 Além de ser uma langue vivante étrangère no contexto de ensino francês, o português é língua minoritária na Guiana Francesa, ou seja, uma língua falada por uma minoria em um território. É também considerada uma língua de migração, quer dizer, falada por locutores originários de um outro território — que não aquele onde tais falantes residem.
} 
Política linguística exterior brasileira e política linguística francesa em contato: o caso do português como língua de herança $(P L H)$ no dispositivo Intervenant en Langue Maternelle na Guiana Francesa

oportunidade de acesso ao universo cultural brasileiro como forma de preservar os laços afetivos com o país de origem.

Mesmo considerando os pontos positivos do dispositivo ILM em favor do português, é preciso destacar que a proposta pedagógica por ele assumida não contempla de forma específica o ensino do português como língua de herança. Entender que, no caso presente, o espaço de atuação não é necessariamente dedicado ao ensino de PLH e que o trabalho do professor (intervenant) deve estar em consonância com as diretrizes do sistema de ensino francês é, sem dúvida, uma diferenciação importante. Mas, ainda assim, o que se percebe, ao analisar o dispositivo ILM, é que os seus pressupostos teóricos abarcam estratégias que se harmonizam com os pressupostos téoricometodológicos para o ensino de português como língua de herança. Dito de outro modo, indubitavelmente, trata-se de um dispositivo que permite, ou seja, que está aberto a um ensino bilíngue e bicultural, podendo, a partir da prática docente, se constituir como um genuíno ensino de PLH. Não à toa que, no desenho institucional do dispositivo, são previstos encontros de formação em que se busca uma reflexão sobre as práticas pedagógicas nas salas de aula, procurando entender as dificuldades dos professores e orientá-los quanto aos desafios enfrentados para melhor atender as necessidades dos alunos.

Sendo assim, no presente artigo, descreveremos brevemente as características gerais do dispositivo ILM para, em seguida, apontarmos as possibilidades que esse dispositivo, integrado ao sistema de ensino francês, oferece para o ensino do PLH. Na segunda parte do artigo, discutiremos a importância da Proposta curricular para o ensino de português como língua de herança (BRASIL, 2020b), documento de referência produzido pelo 
Ministério das Relações Exteriores, como uma fonte de consulta de grande valia para contribuir na formação de professores que atuam no ensino de PLH nas escolas públicas da Guiana Francesa. Ao final, teceremos algumas considerações, sugerindo pontos de observação e melhoria para o ensino-aprendizagem de PLH na Guiana Francesa com base na proposta curricular do Itamaraty.

\section{0 dispositivo Intervenant en Langue Maternelle na Guiana Francesa: uma proposta de ensino para PLH?}

A Guiana Francesa é uma região da França onde a população possui uma grande diversidade cultural e linguística. Além do francês, língua de escolarização, o créole, as línguas indígenas e aquelas oriundas da migração são comumente faladas pelos habitantes da região. Com uma longa história de migração, a comunidade brasileira hoje residente no território francês é bastante significativa. Com exceção do Brasil, a Guiana Francesa é o território da América do Sul com maior proporção de brasileiros. Estima-se que a comunidade possui entre 70 a 80 mil residentes - equiparável à comunidade brasileira na Argentina. Esse número corresponde a mais de um quarto da população da Guiana Francesa, segundo dados oficiais do Ministério das Relações Exteriores do Brasil. ${ }^{6}$

Dada essa conjuntura, é normal de se esperar que boa parte dos alunos matriculados no sistema de ensino na Guiana Francesa seja composta de alunos falantes de português. A esse respeito, o estudo de Léglise, ${ }^{7}$ publicado em 2013, já indicava a significativa

6 Os dados podem ser acessados no portal oficial do Ministério das Relações Exteriores do Brasil. Para mais informações, conferir as referências bibliográficas ao final do artigo.

7 Os dados completos da pesquisa podem ser acessados no portal Recherches Guyanaises. Para mais informações, conferir as 
Política linguística exterior brasileira e política linguística francesa em contato: o caso do português como língua de herança $(P L H)$ no dispositivo Intervenant en Langue Maternelle na Guiana Francesa

parcela de alunos na Guiana Francesa (cerca de 10\%) que tem o português como a primeira língua adquirida ou aprendida durante a primeira socialização. Em seu estudo, a pesquisadora afirma que o português tem uma representatividade de quase 20 $\%{ }^{8}$ no repertório linguístico dos alunos se considerado que ele é também aprendido e adquirido após a primeira socialização. Léglise (2013) destaca, ainda, que se trata da veiculação do português do Brasil, indicando como é expressiva a presença brasileira na região.

Diante desse contexto, notadamente bi/plurilíngue, é que, em 1998, foi criado o dispositivo ILM pela Académie de Guyane para atender falantes de línguas indígenas e minoritárias no território guianense, contratando professores "nativos" "bilíngues (chamados de intervenants). Em sua concepção original, o papel desses professores era favorecer o desenvolvimento da fala e do pensamento das crianças na língua materna, ser representante da cultura do aluno e ser um intermediário entre as famílias e a escola. Atualmente, o objetivo do dispositivo, conforme descrito pelo portal oficial do governo, é " ajudar os alunos a apropriaremse da escola, dar-lhes a oportunidade de desenvolver o domínio da sua língua materna e valorizar a sua cultura para facilitar o desenvolvimento da autoestima e a aquisição da língua francesa". ${ }^{10}$ (Portal oficial da Education Prioritaire de Guyane).

Como dito na introdução deste artigo, o bilinguismo no sistema de ensino francês é previsto pelo próprio Code de

referências bibliográficas ao final do artigo.

8 Considerando que quase 400 dos 2.000 alunos pesquisados declaram ter aprendido o português, consideramos a estatística aproximada de $20 \%$.

9 O conceito de "nativo" é muito problematizado na linguística aplicada (cf. RAJAGOPALAN, 1997). Portanto, usamos a formulação entre aspas para preservar a palavra utilizada no documento original e indicar que queremos, com o uso do termo, definir que nativos são aqueles que têm a língua como língua materna.

10 No original: "aider les élèves à s'approprier l'école, de leur donner la possibilité de développer la maîtrise de leur langue maternelle et de valoriser leur culture afin de faciliter le développement de l'estime de soi et l'acquisition du français" (ACADÉMIE DE GUYANE, 2020d). Para mais informações, conferir as referências ao final deste artigo. 
l'éducation, cabendo a cada académie régionale a definição desse ensino em sua própria rede, conforme as suas especificidades locais. Ademais, o termo língua de herança não é usual na França, sendo mais comum dizer falantes bilíngues, seja por falarem uma língua materna outra que o francês, seja por serem considerados falantes de língua de migração. Nesse contexto, em nível nacional, o ensino bilíngue tem sido contemplado em dois diferentes dispositivos. Quando voltado para as línguas maternas, entendidas no dispositivo como sendo aquelas línguas oficiais de outros países, tal ensino já vem sendo implementado desde a década de 70 do século passado, por meio do dispositivo Enseignements de langue et de culture d'origine (ELCO). Quando voltado para crianças em contexto migratório e recém-admitidas no sistema de ensino francês, tem-se o dispositivo Ressources pour l'accueil et la scolarisation des élèves allophones nouvellement arrivés (EANA). O ELCO é um dispositivo pensado a partir da lógica da língua de acolhimento que visa a estabelecer na escola práticas pedagógicas de inclusão em favor dos alunos, inclusive com atividades extraclasse. Quanto ao EANA, embora traga em seu nome a palavra acolhimento (accueil), o que se percebe, na prática, é que aborda um bilinguismo de transição, ou mesmo de substituição, em que a língua do aluno migrante (allophone ${ }^{11}$ ) será utilizada apenas como facilitadora para escolarização na língua francesa.

Contudo, na Guiana Francesa, onde vigora um contexto linguístico bastante diversificado, os dispositivos existentes não parecem ter sido os mais adequados para atender essa realidade. Em relação às línguas regionais, foram criadas classes bilíngues específicas, uma vez que o estatuto dessas línguas é serem

11 No contexto de ensino francês, os alunos allophones são aqueles cujas línguas primeiras são outras que não o francês. 
Política linguística exterior brasileira e política linguística francesa em contato: o caso do português como língua de herança (PLH) no dispositivo Intervenant en Langue Maternelle na Guiana Francesa

consideradas línguas do patrimônio da França. Já as línguas indígenas, ${ }^{12}$ embora não reconhecidas como línguas regionais, são intensamente presentes no repertório linguístico dos alunos. Mas, não sendo língua regional, língua de migração, tampouco língua oficial de outros países, tal situação não permitia que os alunos falantes dessas línguas indígenas fossem contemplados no dispositivo ELCO.

Desse modo, diferentemente de outros dispositivos de política linguística criados no território europeu da França e, posteriormente, adotados na Guiana Francesa, o ILM é elaborado pela própria Académie de Guyane e pensado especificamente para o contexto guianense. A Académie de Guyane entende que o dispositivo nasce, justamente, a partir da consideração da glotodiversidade e do multiculturalismo guianense pela école, a fim de contribuir para o desenvolvimento cognitivo dos alunos. É, portanto, fruto de uma política linguística genuinamente regional, concretizada a partir do empenho e envolvimento de atores políticos, sociais e pesquisadores locais em benefício das línguas minoritárias presentes no território guianense.

Segundo os documentos oficiais retirados do site Langues de Guyane, o dispositivo ILM possui uma concepção teórica e metodológica própria, apoiada nos trabalhos teóricos de três especialistas em "didática do bi/plurilinguismo": Josiane Hamers, Ellen Byalistok e Jim Cummins. Em síntese, há dois princípios de base que regem o dispositivo ILM:

1. Estudar duas ou mais línguas não produz efeitos negativos sobre o desenvolvimento escolar dos alunos;

12 Na França, as línguas indígenas têm o estatuto de línguas minoritárias. 
2. O uso da língua primeira/materna do aluno contribui para

o seu desenvolvimento escolar, promovendo uma primeira experiência linguística não conflituosa.

Defendendo a ideia de que o uso de duas ou mais línguas na escola é benéfico no processo de ensino-aprendizagem, o dispositivo ILM propõe um trabalho de reflexão junto aos alunos no sentido de valorizar as diferentes línguas do seu repertório linguístico. Dessa forma, o direito de falar a primeira língua dentro da escola é formalmente contemplado na política linguística francesa implementada na Guiana Francesa. É exatamente por essa razão que, mesmo não figurando na categoria de língua regional ou minoritária nos documentos oficiais, o português tem sido uma das línguas contempladas no dispositivo ILM, sobretudo dada a representatividade que possui em relação ao bilinguismo dos alunos. A título de exemplificação, a tabela a seguir (Tabela 1) lista as écoles, as cidades e o número de alunos inscritos em português na Guiana Francesa em classe de portugais, seja em horários atribuídos especificamente a essa langue vivante, seja matriculados em dispositivos específicos como o Intervenant en langue maternelle (ILM) ao longo dos anos 2011 a 2017: 
Política linguística exterior brasileira e política linguística francesa em contato: o caso do português como língua de herança (PLH) no dispositivo Intervenant en Langue Maternelle na Guiana Francesa

\begin{tabular}{|c|c|c|c|}
\hline $\begin{array}{l}\text { Ano 2011-2012 } \\
\text { École/cidade/ } \\
\text { número de } \\
\text { alunos }\end{array}$ & $\begin{array}{l}\text { Ano } 2012-2013 \\
\text { École/cidade/ } \\
\text { número de } \\
\text { alunos }\end{array}$ & $\begin{array}{l}\text { Ano 2014-2015 } \\
\text { École/cidade/ } \\
\text { número de } \\
\text { alunos }\end{array}$ & $\begin{array}{c}\text { Ano 2016- } \\
2017 \\
\text { École/cidade/ } \\
\text { número de } \\
\text { alunos }\end{array}$ \\
\hline $\begin{array}{c}\text { Sulny, St. } \\
\text { Georges, (111) } \\
\text { Léanville, } \\
\text { Régina, (64) } \\
\text { Abriba, } \\
\text { Matoury, (5) } \\
\text { Balata, Matoury, } \\
\text { (2) } \\
\text { Larivot, } \\
\text { Matoury, (15) }\end{array}$ & $\begin{array}{c}\text { Sulny, St. } \\
\text { Georges, (63) } \\
\text { Léanville, } \\
\text { Régina, (67) } \\
\text { Abriba, } \\
\text { Matoury, (19) } \\
\text { Larivot, } \\
\text { Matoury, (7) } \\
\text { Balata, Matoury, } \\
\text { (8) }\end{array}$ & $\begin{array}{c}\text { Sulny, St. } \\
\text { Georges, (47) } \\
\text { Léanville, } \\
\text { Régina, (36) }\end{array}$ & $\begin{array}{c}\text { Sulny, St. } \\
\text { Georges, (35) } \\
\text { Léanville, } \\
\text { Régina, (45) }\end{array}$ \\
\hline $\begin{array}{c}\text { Total: } 197 \\
\text { alunos }\end{array}$ & $\begin{array}{c}\text { Total: } 164 \\
\text { alunos }\end{array}$ & Total: 83 alunos & $\begin{array}{c}\text { Total: } 81 \\
\text { alunos }\end{array}$ \\
\hline
\end{tabular}

Fonte: Elaborada pela autora a partir de Académie de Guyane (2020b).

É preciso pontuar, ainda, que é nas cidades do leste da Guiana Francesa (Saint-Georges-de-l'Oyapock e Régina), mais próximas à fronteira com o Brasil, que se registra um maior número de crianças falantes de português (69\% e 42,5\%, respectivamente) (LÉGLISE, 2013).

$\mathrm{O}$ que se observa, a partir desses três exemplos de dispositivos de política linguística que brevemente foram apresentados (ELCO, EANA e ILM), é que o bilinguismo tem sido foco de atenção nas práticas educativas francesas, pelo menos desde 1970. O contexto fronteiriço da França hexagonal e os fluxos migratórios de ex-colônias e demais países europeus fizeram com que a diversidade linguística se tornasse uma realidade no sistema escolar. Com isso, o ensino bilíngue acabou 
sendo formalmente inserido no Code de l'éducation para ser adotado na rede de ensino conforme as necessidades regionais.

Embora, como já dito, o termo português como língua de herança não seja empregado na França, observa-se que a perspectiva presente nos diferentes documentos que regem o ensino bilíngue guarda correlação com o ensino de português como língua de herança. No caso do ILM, seus objetivos de ensino nos encorajam a dizer que contemplam as premissas que comumente se empregam ao ensino do português como língua de herança. Sabemos que o termo língua de herança se desenvolveu primeiramente na literatura de matriz anglo-saxã (heritage language), sendo empregado a partir de sua adoção em contexto de uma política linguística implementada no Canadá (SILVA, 2018). Os estudos sobre língua de herança são relativamente recentes no campo dos Estudos da Linguagem, não havendo ainda uma unanimidade quanto ao sentido e alcance do termo. Alguns optam por utilizar conjuntamente os termos "língua de herança/comunidade"; outros preferem termos correlatos, como "língua minoritária", "língua étnica", "língua ancestral", "língua internacional" (PEYTON; RANARD; MCGINNIS, 2001 apud SILVA, 2018).

No meio acadêmico, duas definições de língua de herança vêm sendo citadas com frequência: a de Valdés (2000; 2005) e a de Van Deusen-Scholl (2003). Valdés (2000) considera que a LH é uma língua diferente da dominante na sociedade local, entendendo que esse termo "tem sido amplamente utilizado para se referir a línguas - não faladas na sociedade - e não majoritárias, faladas por grupos, muitas vezes conhecidos como minorias linguísticas" (VALDÉS, 2005, p. 411). Por sua vez, Van Deusen-Scholl (2003) parte de uma definição mais 
Política linguística exterior brasileira e política linguística francesa em contato: o caso do português como língua de herança (PLH) no dispositivo Intervenant en Langue Maternelle na Guiana Francesa

abrangente do termo uma vez que compreende que a LH é aquela que engloba "um grupo que inclui desde nativos fluentes a não falantes da LH, os quais podem estar a gerações de distância do familiar emigrante, mas que se sentem culturalmente ligados à língua e têm um vínculo cultural com a comunidade que se comunica por esse idioma" (VAN DEUSEN-SCHOLL, 2003 apud MORINI, 2018, p. 1.236-1.247). Independentemente da questão terminológica, é preciso reconhecer o que, de fundo, se opera quando se busca efetivar um ensino bilíngue em que uma das línguas tem relação com a origem do aluno e seus laços sociais, culturais e/ou históricos.

Atualmente, o ensino de língua de herança abarca uma noção que está "além da aquisição e/ou aprendizagem de uma língua e dos resultados de proficiência linguística" (YONAHA; MUKAI, 2016, p. 205), devendo estar relacionada com a "transmissão tanto linguística como cultural de um legado com forte carga emocional” (YONAHA; MUKAI, 2016, p. 205). A esse respeito, como afirma Silva, citando Souza:

[...] o termo herança "faz parte de um processo dialógico entre passado (isto é, as experiências sociolinguísticas de pais em seus países de origem) e presente (isto é, as experiências sociolinguísticas de pais e de seus filhos nos países que os acolhem), é preciso se afastar de conceitos estigmatizantes do falante de herança e também considerar as questões identitárias envolvidas no processo de aquisição da LH (inclusão/exclusão, pertencimento/não pertencimento), bem como o contexto sociocultural no qual a LH está inserida. (SOUZA, 2016, p. 308 apud SILVA, 2018).

Quando se fala em ensino bilíngue na França, é preciso reconhecer a forte tradição monolíngue do país. Atualmente, a centralidade do francês ainda permanece. Mas isso não significa 
que não tenha havido certa evolução. A instituição de uma política bilíngue é uma mostra de como o sistema de ensino se abriu para o ensino concomitante de outras línguas, sobretudo em regiões de fronteira e de intensa migração. O dispositivo ILM é um exemplo importante, pois, como dito, é um dispositivo concebido, criado e implementado regionalmente, visando a contemplar línguas indígenas. A inserção tardia do português nesse dispositivo somente reforça o grau de autonomia regional para implementar um ensino bilíngue que busca respeitar a origem dos alunos e valorizar a língua e cultura para inserção no contexto escolar.

A título de exemplificação, podemos observar que, dentro do construto teórico ${ }^{13}$ do dispositivo, são apresentados três argumentos que concorrem para a defesa de um ensino de línguas e culturas regionais dentro do sistema de ensino na Guiana Francesa, a fim de se relativizar o modelo de ensino monolíngue francês. Conforme veremos a seguir, tais argumentos ressaltam a importância de um ensino bilíngue que valorize a língua do aluno, como herança linguístico-cultural:

1. Ético: exigindo que a questão seja pensada sob um ponto de vista filosófico. A construção da identidade não se faz negando o conhecimento dela própria? Como buscar uma relação pacificada e equilibrada com o outro se não conhecemos sua origem, sua cultura, sua história? Ou seja, trata-se claramente de se preservar a herança linguístico-cultural e permitir que, ao invés de ser negligenciada pela escola, encontre nela os meios para que seja transmitida e preservada. A escola não deve ser o "cemitério" das línguas não oficiais.

\footnotetext{
13 O construto teórico do dispositivo está disponível no documento Cadre réglementaire et didactique des habilitations à enseigner une/em L1. Para mais informações, consultar o portal oficial Langues de Guyane disponibilizado nas referências bibliográficas.
} 
Política linguística exterior brasileira e política linguística francesa em contato: o caso do português como língua de herança $(P L H)$ no dispositivo Intervenant en Langue Maternelle na Guiana Francesa

2. Político: o francês foi, antes de tudo, uma língua de colonização imposta aos falantes. Nesse sentido, permitir a expressão dessas línguas que antes foram combatidas ou silenciadas é um gesto no sentido de romper com o monolinguismo colonizador e respeitar a diversidade linguística local. Ou seja, trata-se de favorecer processos de integração e não de exclusão.

3. Cognitivo: não há nenhuma evidência científica de que o bi/ plurilinguismo dos alunos seja prejudicial ao desenvolvimento cognitivo e nem mesmo que acarrete prejuízos ao desenvolvimento escolar. Ou seja, trata-se dos efeitos benéficos da interculturalidade a fim de favorecer o desempenho dos alunos.

Ademais, as atribuições previstas para o professor do dispositivo reforçam ainda mais o quanto a concepção de ensino está voltada para objetivos visados para o ensino em contexto de língua de herança. No documento referencial de trabalho do ILM (ACADÉMIE DE GUYANE, 2019), são apresentados três objetivos do trabalho do Intervenant en langue maternelle:

- Fomentar o desenvolvimento da linguagem e do pensamento dos alunos na sua língua materna. Realizar atividades que visem à estruturação da língua materna dos alunos. Em consulta com os professores, organizar os conteúdos de aprendizagem em uma progressão levando em consideração os programas e habilidades no final do ciclo.

- Ser representante da cultura das crianças na escola. Um profissional que contribua para questões de língua materna e cultura dos alunos. Informar os professores sobre as práticas culturais das famílias. Sugerir aos professores projetos sobre temas culturais. 
- Ser o intermediário entre as famílias e a escola. Auxiliar o diretor e os professores durante as reuniões com os pais. Participar de ações de mediação com famílias. (ACADÉMIE DE GUYANE, 2019, tradução nossa). ${ }^{14}$

No manual do Intervenant, documento que prescreve orientações de trabalho ao professor antes, durante, depois da aula, bem como atividades transversais, observa-se, igualmente, uma preocupação com a utilização da L1 do aluno nas diversas fases do processo de ensino-aprendizagem. Vejamos a seguir o Quadro 1:

\section{Quadro 1 - Referencial de trabalho do Intervenant en langue maternelle}

\begin{tabular}{|l|l|l|}
\hline \multicolumn{2}{|c|}{ Atividade A 1: Antes da aula } & \multicolumn{1}{c|}{ Descrição } \\
\hline \multirow{4}{*}{ A1T1 } & $\begin{array}{l}\text { Observar, problematizar, } \\
\text { imaginar. } \\
\text { Situar a progressão dos } \\
\text { alunos em observância } \\
\text { ao Socle commun } \\
\text { de compétences de de } \\
\text { connaissances et de de } \\
\text { culture. }\end{array}$ & $\begin{array}{l}\text { lenaração para a progressão do } \\
\text { conteúdo, das sequências didáticas } \\
\text { e das aulas. } \\
\text { Conceber e adaptar ferramentas } \\
\text { aprendizagens a serem adquiridas } \\
\text { na língua e na cultura maternas } \\
\text { (L1), de forma a poder transferi-las } \\
\text { para a língua de escolarização. }\end{array}$ \\
\hline A1T2 & $\begin{array}{l}\text { Identificar, organizar } \\
\text { preparar o aprendizado. }\end{array}$ & $\begin{array}{l}\text { Definir os objetivos educacionais; } \\
\text { organizar os conteúdos; escolher } \\
\text { os métodos de ensino; conceber } \\
\text { materiais didáticos; escolher } \\
\text { instrumentos de avaliação. }\end{array}$ \\
\hline
\end{tabular}

14 No original: "- Favoriser le développement du langage et de la pensée des élèves dans leur langue maternelle. Conduire des activités visant à la structuration de la langue maternelle des élèves. En concertation avec les enseignants, organiser ces apprentissages dans une progression tenant compte des programmes et des compétences de fin de cycle.

- Être le représentant, dans l'école, de la culture des enfants. Personne-ressource pour les questions de langue et de culture maternelles des élèves. Informer les enseignants sur les pratiques culturelles des familles. Suggérer aux enseignants des projets sur des thèmes culturels.

- Être l'intermédiaire entre les familles et l'École. Assister le directeur et les enseignants lors des rencontres et des réunions avec les parents. Participer à des actions de médiation auprès des familles." (ACADÉMIE DE GUYANE, 2019). 
Política linguística exterior brasileira e política linguística francesa em contato: o caso do português como língua de herança $(P L H)$ no dispositivo Intervenant en Langue Maternelle na Guiana Francesa

\begin{tabular}{|c|c|c|}
\hline \multicolumn{2}{|c|}{ Atividade A 2: Durante a aula } & Descrição \\
\hline A2T3 & $\begin{array}{l}\text { Preparar um clima } \\
\text { adequado para a } \\
\text { aprendizagem. }\end{array}$ & $\begin{array}{l}\text { Criar uma atmosfera e condições } \\
\text { favoráveis para a aprendizagem; } \\
\text { discutir com os alunos com o intuito } \\
\text { de criar uma relação de confiança e } \\
\text { captar a atenção deles. }\end{array}$ \\
\hline $\mathrm{A} 2 \mathrm{~T} 4$ & $\begin{array}{lr}\text { Envolver os alunos } \\
\text { no processo de } \\
\text { aprendizagem (buscar } \\
\text { conhecimentos já } \\
\text { adquiridos, despertar o } \\
\text { interesse dos alunos). }\end{array}$ & $\begin{array}{l}\text { Identificar e sistematizar os } \\
\text { conhecimentos já trazidos pelos } \\
\text { alunos; fazer a conexão entre o } \\
\text { conhecimento anterior do aluno } \\
\text { e o objetivo do curso; despertar } \\
\text { o interesse do aluno em adquirir } \\
\text { novas habilidades. }\end{array}$ \\
\hline A2T5 & $\begin{array}{l}\text { Iniciar concretamente } \\
\text { a fase de aprendizagem } \\
\text { (ensino baseado na } \\
\text { pedagogia interativa). }\end{array}$ & $\begin{array}{l}\text { Apresentar o tema e as tarefas } \\
\text { a serem realizadas; adaptar } \\
\text { e desenvolver estratégias } \\
\text { pedagógicas de acordo com as } \\
\text { habilidades de escuta, habilidades e } \\
\text { progresso dos alunos; alternar fases } \\
\text { de acompanhamento dos alunos e } \\
\text { trabalho de tutoria/em autonomia } \\
\text { desses alunos. }\end{array}$ \\
\hline \multicolumn{2}{|c|}{ Atividade A3: Após a aula } & Descrição \\
\hline A3T6 & $\begin{array}{l}\text { Fazer uma avaliação da } \\
\text { aula. }\end{array}$ & $\begin{array}{l}\text { Verificar o cumprimento dos } \\
\text { objetivos planejados a partir dos } \\
\text { resultados obtidos; identificar } \\
\text { situações críticas ou resultados } \\
\text { inesperados e levá-los em } \\
\text { consideração para a preparação do } \\
\text { programa e da aula; ter a atitude de } \\
\text { autoavaliação durante o curso para } \\
\text { melhorar a prática docente. }\end{array}$ \\
\hline A3T7 & $\begin{array}{l}\text { Avaliar os resultados dos } \\
\text { trabalhos dos alunos. }\end{array}$ & $\begin{array}{l}\text { Avaliar o conteúdo e/ou a evolução } \\
\text { das diversas atividades ou tarefas } \\
\text { realizadas pelos alunos ao nível da } \\
\text { aprendizagem de conhecimentos; } \\
\text { fazer avaliação quantitativa (nota) e } \\
\text { qualitativa do trabalho do aluno de } \\
\text { acordo com as formas ou critérios } \\
\text { estabelecidos. }\end{array}$ \\
\hline
\end{tabular}




\begin{tabular}{|c|c|c|}
\hline A3T8 & $\begin{array}{l}\text { Usar os resultados da } \\
\text { revisão e avaliação do } \\
\text { curso para melhorar } \\
\text { estratégia de ensino. }\end{array}$ & $\begin{array}{l}\text { Analisar a metodologia utilizada; } \\
\text { fazer um balanço da sua prática } \\
\text { pedagógica; planejar outras } \\
\text { estratégias pedagógicas para } \\
\text { melhorar a qualidade do processo } \\
\text { de aprendizagem; analisar a } \\
\text { importância das mediações } \\
\text { realizadas nas aulas. }\end{array}$ \\
\hline \multicolumn{2}{|c|}{$\begin{array}{c}\text { Atividade A4: } \\
\text { Atividades transversais }\end{array}$} & Descrição \\
\hline A4T9 & $\begin{array}{l}\text { Identificar e organizar os } \\
\text { recursos educacionais. }\end{array}$ & $\begin{array}{l}\text { Determinar os materiais necessários } \\
\text { para atingir os objetivos da aula; } \\
\text { contribuir para o ensino da língua } \\
\text { materna e para a construção de um } \\
\text { dicionário de línguas locais. }\end{array}$ \\
\hline A4T10 & $\begin{array}{l}\text { Estabelecer e manter } \\
\text { relações com o meio } \\
\text { local: social, familiar, } \\
\text { cultural, tradicional. }\end{array}$ & $\begin{array}{l}\text { Definir e/ou implementar } \\
\text { metodologia de interação com } \\
\text { o meio; estabelecer trocas } \\
\text { construtivas com potenciais atores } \\
\text { (professores, autoridades locais), } \\
\text { tornando-os parceiros; coletar, } \\
\text { avaliar e utilizar as informações } \\
\text { desses parceiros para aprimorar e } \\
\text { atualizar as atividades educacionais. }\end{array}$ \\
\hline A4T11 & $\begin{array}{l}\text { Estabelecer e manter } \\
\text { relações com as } \\
\text { autoridades locais, pais } \\
\text { de alunos, colegas de } \\
\text { trabalho do dispositivo } \\
\text { ILM, a proposta } \\
\text { pedagógica, etc. }\end{array}$ & $\begin{array}{l}\text { Discutir suas práticas no âmbito } \\
\text { dos espaços institucionais } \\
\text { da comunidade educacional; } \\
\text { avaliar, sistematizar e utilizar } \\
\text { as informações da comunidade } \\
\text { educacional para aprimorar os } \\
\text { processos de ensino-aprendizagem- } \\
\text { avaliação; desenvolver uma } \\
\text { atividade de mediação entre as } \\
\text { famílias e o sistema escolar. }\end{array}$ \\
\hline A4T12 & $\begin{array}{l}\text { Respeitar as regras } \\
\text { republicanas, as políticas } \\
\text { educacionais. }\end{array}$ & $\begin{array}{l}\text { Garantir o cumprimento das normas, } \\
\text { procedimentos e políticas vigentes } \\
\text { em seu ambiente profissional; } \\
\text { avaliar e concluir os resultados dos } \\
\text { alunos de acordo com as normas em } \\
\text { vigor. }\end{array}$ \\
\hline
\end{tabular}


Política linguística exterior brasileira e política linguística francesa em contato: o caso do português como língua de herança $(P L H)$ no dispositivo Intervenant en Langue Maternelle na Guiana Francesa

\begin{tabular}{|l|l|l|}
\hline \multirow{4}{*}{ A4T13 } & $\begin{array}{l}\text { Determinar os pontos fortes e } \\
\text { Atualizar seus } \\
\text { conhecimentos } \\
\text { e promover o } \\
\text { aprimoramento contínuo } \\
\text { do ILM. }\end{array}$ & $\begin{array}{l}\text { as aspectos que precisam ser } \\
\text { aprimorados para um melhor } \\
\text { (pedagogia, didática, metodologia, } \\
\text { etc.). }\end{array}$ \\
\hline
\end{tabular}

Fonte: Académie de Guyane (2019).

Desse modo, ao menos do ponto de vista formal, é possível vislumbrar, a partir das referências pesquisadas e aqui brevemente relatadas, que, no dispositivo ILM, os objetivos de ensino para língua de herança também se mostram presentes, podendo ser sintetizados conforme se segue:

- Desenvolvimento das competências do aluno na sua língua de origem;

- Desenvolvimento e consolidação do bi/plurilinguismo;

- Desenvolvimento e expansão do conhecimento sobre a(s) cultura(s) e o(s) país(es) de origem;

- Apoio no processo de integração e orientação na escola do país de acolhimento;

- Apoio no processo de integração e orientação na sociedade do país de acolhimento;

- Promoção da intervenção e competência intercultural.

Por essas razões, entendemos que o ILM, como dispositivo originalmente concebido para o ensino de línguas e culturas regionais e minoritárias na Guiana Francesa, tem, a partir dos seus pressupostos teóricos e objetivos de atuação, semelhanças estreitas com os pressupostos teórico-metodológicos pensados para o ensino de português como língua de herança. Estando o português formalmente inserido e contemplado no dispositivo 
ILM, entendemos que se configura aí um contexto em que o ensino do português é adotado como língua de herança nas escolas públicas da Guiana Francesa.

Indo mais além, entendemos também que tal espaço para o ensino do português é um locus privilegiado, tendo em vista se tratar do ensino de língua de herança promovido e organizado através das instituições de ensino do país de acolhimento, em sua rede estatal de educação. Ou seja, diferentemente de outros contextos, em que o ensino é dispensado através dos consulados ou embaixadas dos países de origem, ou, então, por meio de entidades não governamentais (associativismo local), o PLH, na Guiana Francesa, está integrado na carga horária e faz parte do ensino regular dos alunos. Esse é um aspecto que merece ser destacado e valorizado, ainda que, frise-se, o ensino não esteja sendo totalmente concebido e adaptado para o público falante de português.

Não obstante esse aspecto positivo, é preciso fazer algumas observações e reconhecer algumas dificuldades para que o ensino do PLH se torne mais harmonizado e adaptado às necessidades do público falante. Primeiro, porque o fato de se ter uma política linguística declarada, no plano formal, não necessariamente implica dizer que ela será de fato implementada. Sabemos que, entre a formulação e a implementação, diversos problemas existem, de modo que o discurso oficial não pode ser tomado como pressuposto de efetividade. Como já ressaltamos, a França possui uma forte tradição monolíngue e há razões para se pensar que ainda remanesceriam condições estruturais e comportamentais a privilegiar o ensino do francês em relação ao das demais línguas. Nesse sentido, podemos inclusive destacar que, do ponto de vista prático, o ensino do português dispensado nas classes de ILM está voltado a ajudar o aluno para a aprendizagem do 
Política linguística exterior brasileira e política linguística francesa em contato: o caso do português como língua de herança $(P L H)$ no dispositivo Intervenant en Langue Maternelle na Guiana Francesa

francês, ideia esta que se aproxima mais de um bilinguismo de transição. Ou seja, embora haja um discurso oficial de abertura ao bilinguismo e de respeito às origens dos alunos, ainda permanece, na prática educativa, a instrumentalização da língua do aluno, quer seja a língua vista como um problema, quer seja como um recurso. Nesse sentido, conforme já argumentamos, em outro trabalho, a "língua materna dos alunos é significada como um problema na medida em que ela poderia representar um obstáculo à aprendizagem e à escolarização em francês. A língua seria um recurso na medida em que ela é valorizada e reconhecida para contribuir na aquisição do francês". (SILVA, 2020, p. 235).

Outro problema que podemos destacar diz respeito ao recrutamento e à seleção de professores. Os intervenants não são professores da rede de ensino regular, mas sim contratados para assumirem determinados postos de trabalho nas localidades especificadas em editais. São vínculos de trabalho mais precários, em que são contratados profissionais que não necessariamente possuem formação superior para lecionarem. O nível de proficiência na língua materna acaba sendo o requisito mais importante, razão pela qual também não se exige que seja contratado um professor "nativo". A fim de suprir certas carências na formação desses profissionais, a Académie de Guyane tem procurado realizar cursos e oficinas com esses intervenants com intuito de desenvolver competências específicas no ensino-aprendizagem da língua e na elaboração de programas de ensino. No âmbito dessas formações realizadas pela Académie de Guyane, tem sido evidenciado que há uma procura de referenciais de ensino e de materiais didáticos em língua portuguesa, em documentos oficiais brasileiros e em 
sites governamentais, além, é claro, de outras fontes de consulta disponíveis na internet.

Portanto, essa dificuldade enfrentada pelos professores que atuam com o português no âmbito do dispositivo ILM se constitui como um importante ponto de reflexão acerca da possibilidade de contribuição que a Proposta curricular para o ensino de português como língua de herança (BRASIL, 2020b), recentemente publicada pelo Ministério das Relações Exteriores do Brasil, pode representar para o aperfeiçoamento do ensino do português como língua de herança na Guiana Francesa. A seguir, apresentaremos brevemente esse documento, resultado do esforço conjunto de pesquisadores e professores, que visa a contribuir para a sistematização de atividades relacionadas ao português como língua de herança.

\section{Proposta curricular para o ensino de português como língua de herança: uma importante fonte de consulta e referência para o PLH na Guiana Francesa}

Nos últimos anos, o Ministério das Relações Exteriores tem empreendido esforços para conformar uma política linguística do Estado brasileiro direcionada para o ensino de português no exterior em suas mais diversas abordagens. Uma importante iniciativa nesse sentido foi a recente publicação da Proposta curricular para o ensino de português como língua de herança (BRASIL, 2020b, Apresentação), que "visa a contribuir para a sistematização de atividades relacionadas ao português como língua de herança, configurando-se como estrutura de apoio nas diversas fases e concretudes do processo de ensino". 
Política linguística exterior brasileira e política linguística francesa em contato: o caso do português como língua de herança $(P L H)$ no dispositivo Intervenant en Langue Maternelle na Guiana Francesa

É sabido que a manutenção de vínculos de identidade de membros da comunidade com o país de origem, com a língua e com a cultura é favorecida com um ensino que seja capaz de atender às expectativas de pais com relação ao bilinguismo dos filhos. É com base nessa premissa e reconhecendo complexidades e desafios inerentes à sistematização nessa área que o Ministério das Relações Exteriores buscou produzir a referida proposta, com o intuito de servir como "um documento norteador de escolhas relacionadas a programas de ensino de português como língua de herança a serem feitas por instituições brasileiras (formais e informais) que atuam em vários países com presença de imigrantes brasileiros". (BRASIL, 2020b, Apresentação). Nesse sentido, a publicação do material é importante, pois é capaz de suprir lacunas existentes quanto às especificidades do ensino de PLH, podendo servir como diretriz de trabalho para professores e formadores que atuam na área.

É preciso ressaltar que o Itamaraty é o órgão do governo brasileiro que busca implementar políticas linguísticas para o português no exterior e assim o faz pela Divisão de Temas Educacionais e Língua Portuguesa (DELP). Desse modo, a DELP desenvolve a sua atuação em torno de alguns eixos: por meio da sua rede de ensino no exterior (Centros Culturais Brasileiros, Núcleo de Estudos Brasileiros e Leitorados), apoio a iniciativas locais em favor da comunidade brasileira e parcerias com outros órgãos de governo para aplicação de exames nacionais, como, por exemplo, o Celpe-Bras e o Encceja, realizados conjuntamente com o Ministério da Educação. Contudo, é preciso dizer que, na Guiana Francesa, não existe, atualmente, nenhuma instituição brasileira formal (Núcleo de Estudos Brasileiros ou Centro Cultural Brasileiro) que ofereça cursos de português. Desse 
modo, o ensino do português em território guianense parte de uma iniciativa vinculada ao Ministère de l'Éducation Nationale da França, por meio de sua autarquia regional, a Académie de Guyane. Coube, portanto, às autoridades educacionais locais a decisão de incluir o ensino do português na rede de ensino da Guiana Francesa. Essa inclusão do português se deu em todos os níveis de ensino, sendo contemplado tanto no ensino regular, desde os anos iniciais (école maternelle) até os anos finais (collège e lycée), quanto em dispositivos específicos, como, por exemplo, o ILM, objeto de estudo neste artigo.

Na Guiana Francesa, mais especificamente no âmbito do processo de implementação-avaliação do ILM, a utilização de diretrizes do Ministério da Educação do Brasil (MEC) já tem se constituído como uma fonte material de consulta por parte de formadores e professores. Nesse particular, tem-se que destacar que, conforme o último curso de formação desenvolvido pela equipe Groupes recherche action (G.R.Ac), Séminaires \& Formations d'Initiative Locale (F.I.L) da Académie de Guyane, ocorrido nos dias 2 a 3 de março de 2020, ficou evidente que, dentre os aspectos a serem melhorados no trabalho dos professores nas classes de ILM para o português, está a carência de um material pedagógico mais atrativo e adaptado. Ou seja, um dos principais desafios com que os professores do dispositivo ILM se deparam é a situação insatisfatória relacionada aos manuais e outros materiais didáticos específicos. A título de exemplificação, a formadora do grupo de português, Atilas Cardoso, valeu-se da Base nacional comum curricular do MEC para realizar a formação dos professores na école Léanville, localizada na cidade Régina, na Guiana Francesa. No relatório avaliativo produzido pela formadora, disponível no site da Académie de Guyane, assim está descrito: 
Política linguística exterior brasileira e política linguística francesa em contato: o caso do português como língua de herança (PLH) no dispositivo Intervenant en Langue Maternelle na Guiana Francesa

A formação teve início com a apresentação do BNCC Base Nacional Comum Curricular - do Ministério da Educação do Brasil, bem como a sua equivalência com o sistema de ensino francês.

O BNCC é um documento que regulamenta o aprendizado essencial para o trabalho nas escolas públicas e privadas brasileiras de educação infantil, ensino fundamental e médio. $^{15}$ (ACADÉMIE DE GUYANE, 2020, p. 1).

No documento, podemos perceber que a dificuldade em se obter material pedagógico mais atrativo e mais adaptado tem sido uma queixa comum dos professores de português que atuam no âmbito do dispositivo ILM. Reproduzimos, a seguir, trechos da avaliação em que a formadora Atilas Cardoso propõe diferentes materiais didáticos para os professores que atuam no ILM:

Quanto à obtenção de materiais educacionais mais atrativos e adequados: aconselhei-os a usar materiais encontrados na internet. Ofereci a eles sites brasileiros confiáveis de educação, materiais originais e canais de vídeos no YouTube. Como não há conexão com a internet na escola, nem sempre é fácil usar histórias, músicas, etc. Expliquei aos professores como baixar do YouTube em formato MP3 ou MP4 para que possam usar em sala de aula sem a necessidade de conexão à internet. ${ }^{16}$ (ACADÉMIE DE GUYANE, 2020b, p. 1).

Como pode ser observado, há um aconselhamento expresso pela equipe Groupes recherche action (G.R.Ac), Séminaires \&

15 No original: "La formation a commencé par la présentation du BNCC - Base Nacional Comum Curricular — du Ministère de l'Éducation du Brésil, ainsi que son équivalence avec le système d'Education français. Le BNCC est un document qui réglemente les apprentissages essentiels à travailler dans les écoles publiques et privées brésiliennes d'éducation de la petite enfance, de l'école élémentaire et du lycée." (ACADÉMIE DE GUYANE, 2020c, p. 1). Para maiores informações, conferir as referências ao final deste artigo.

16 No original: "En ce qui concerne l'obtention de matériels pédagogiques plus attractifs et adaptés : Je leur ai conseillés d'utiliser des supports trouvés sur internet. Je leur ai fourni des sites fiables de l'éducation nationale brésilienne, des documents originaux et des chaines YouTube pour les vidéos. Étant donné qu'il n'y a pas de connexion Internet à l'école, il n'est pas toujours facile d'utiliser des contes, des musiques, etc. J'ai expliqué aux enseignants comment télécharger à partir de YouTube au format MP3 ou MP4, ainsi ils peuvent utiliser en salle de classe sans avoir besoin d'être connecté sur internet." (ACADÉMIE DE GUYANE, 2020c, p. 1). 
Formations d'initiative locale (F.I.L) da Académie de Guyane para que os professores se valham de parâmetros curriculares e materiais didáticos específicos para a língua portuguesa em sites confiáveis da educação nacional brasileira. Há, portanto, uma proposta clara de buscar referências em documentos oficiais brasileiros que sirvam de parâmetros seguros para o ensino do português no âmbito do dispositivo ILM.

A partir desse relatório avaliativo do grupo G.R.Ac, podemos perceber uma oportunidade de aproveitamento das diretrizes do ensino de PLH do Itamaraty diretamente na implementação de um dispositivo previsto dentro da política linguística francesa. Ou seja, retomando o título do artigo, o que temos aqui são políticas linguísticas em contato: de um lado, a política linguística exterior brasileira prevendo diretrizes para o ensino do PLH e, de outro, a própria política linguística francesa em favor do português. O próprio Itamaraty já vislumbra essa oportunidade quando assume explicitamente que quaisquer instituições de ensino poderão se valer do material produzido:

Embora pensadas a partir das necessidades de sua rede de postos, as propostas não se destinam exclusivamente ao ensino de português pelos centros culturais e núcleos. Professores, pesquisadores e estudantes de quaisquer instituições poderão beneficiar-se desse pioneiro esforço de reflexão como referência para o desenvolvimento de suas práticas docentes e de pesquisa. (BRASIL, 2020b, p. 7).

Considerando que as políticas de educação bilíngue na esfera pública têm sido fortemente valorizadas no âmbito das políticas linguísticas educacionais, é fundamental reconhecer a importância dessa oportunidade de aplicação de uma proposta curricular para o ensino de PLH na rede pública de outro país. 
Política linguística exterior brasileira e política linguística francesa em contato: o caso do português como língua de herança (PLH) no dispositivo Intervenant en Langue Maternelle na Guiana Francesa

Mas é claro que essa aplicação não pode ocorrer sem considerar certas especificidades e particularidades de cada contexto. Nesse sentido, podemos sugerir alguns pontos de reflexão para serem considerados no planejamento das atividades.

Um primeiro aspecto que podemos sugerir é pensar na própria concepção de bilinguismo. É preciso recusar uma concepção baseada em um bilinguismo de transição, em que o aluno se torna monolíngue em duas línguas. Em contextos de bilinguismo, as pesquisas mais recentes trazem a concepção de translinguismo, em que se valoriza o repertório linguístico do aluno, para além das línguas nomeadas (português e francês). Conforme visto em García, a translinguagem abarca as múltiplas práticas discursivas que os bilíngues usam para dar sentido aos seus mundos bilíngues ou plurilíngues (GARCÍA, 2009). A abordagem translinguística aplicada ao bilinguismo favorece a troca de experiências, a herança cultural do aluno e os valores partilhados por aquela comunidade de fala. Distinções entre a língua da escola e a língua de casa não devem prevalecer em contexto de ensino bilíngue, e o ensino do PLH não deve ser pautado apenas no domínio da língua portuguesa. É necessário que o professor de PLH tenha consciência de toda essa interculturalidade que caracteriza o contexto de ensino desses alunos, buscando construir em sala de aula um espaço dialógico em que língua, cultura e identidade interagem entre si. A esse respeito, Mendes pontua:

[...] professores de PLH, desse modo, precisam compreender a complexidade desse processo e ter ferramentas para analisar cada situação em sua especificidade (e são muitas) e tomar as decisões necessárias para o planejamento de cursos e para a produção de materiais instrucionais, entre outras coisas. Em suma, não basta apenas uma formação que dê conta 
do domínio da língua a ser ensinada, mas que os prepare para compreender os elementos que estão em jogo quando interagimos em português, sendo ela a línguacultura brasileira ou outra língua-cultura em português. (MENDES, 2012, p. 22).

Quando a autora se refere à língua-cultura brasileira, entendemos que aqui reside um outro aspecto importante que também merece ser discutido. Considerando que o Brasil é um país com tradição monolíngue, é necessário pensar em um ensino de PLH para além da língua oficial. O português é língua de colonização, mas em território nacional, diversas outras línguas compõem o patrimônio cultural brasileiro. É preciso que, no ensino de PLH, o conteúdo cultural valorize todo aspecto da cultura do aluno, do seu entorno e das suas origens. Nesse sentido, o português falado pela população brasileira residente na Guiana Francesa é influenciado por aspectos da cultura indígena e expressões típicas locais, por exemplo. Portanto, restringir o ensino como sendo língua-cultura em português pode significar a desvalorização da própria herança trazida pelo aluno, que, dada a existência dessa interculturalidade que mencionamos, não pode ser pautada em uma única língua portuguesa padrão, tampouco, em somente uma única cultura. Ao desconsiderar tais aspectos, corre-se o risco de homogeneizar o ensino, retomando a lógica monolíngue e deixando de lado toda a riqueza cultural do Brasil.

Esses aspectos aqui pontuados são importantes e precisam ser levados em consideração quando da adoção da Proposta curricular para o ensino de português como língua de herança (BRASIL, 2020b), do Itamaraty. Esse manual é, sem dúvida, um documento de referência que merece ser consultado, mas não pode ser adotado de forma acrítica, como se fosse válido 
Política linguística exterior brasileira e política linguística francesa em contato: o caso do português como língua de herança (PLH) no dispositivo Intervenant en Langue Maternelle na Guiana Francesa

para todos os contextos. De certo modo, o Itamaraty já traz essa preocupação, tendo em vista que lançou propostas curriculares para países de língua oficial espanhola e de língua oficial portuguesa. Por seu caráter de proposta, o conteúdo apresentado permite uma ampla possibilidade de adaptação para atender objetivos específicos de cada contexto de ensino, de diferentes países e regiões.

Por fim, entendemos que a discussão realizada neste artigo evidencia a importância de termos propostas curriculares para o PLH no exterior, a exemplo do que dispomos para o ensino em território nacional. A existência desse documento permite que o ensino do português no exterior tenha um conteúdo nacional e com parâmetros que estejam mais harmonizados com as melhores práticas pedagógicas. A possibilidade de a Proposta curricular para o ensino de português como língua de herança (BRASIL, 2020b) do Itamaraty ser utilizada como referência para políticas estatais bilíngues de outros países é igualmente um fator que corrobora a importância das propostas curriculares para o ensino do PLH no exterior.

\section{Considerações finais}

Este artigo procurou discutir o dispositivo de política linguística francesa Intervenant en Langue Maternelle (ILM) como uma possibilidade de ensino de português como língua de herança. Para tanto, na parte introdutória deste artigo, argumentamos que, pari-passu a um crescimento do interesse acadêmico a respeito do ensino de língua de herança, há também uma maior preocupação por parte de gestores da educação de diferentes países em prover seus sistemas de ensino com 
instrumentos de educação bilíngue. Tais medidas permitem oferecer aos alunos falantes de outras línguas um ambiente escolar que, para além da integração no país, também assegura o pleno desenvolvimento do aluno, em relação às suas origens, identidades e patrimônio linguístico-cultural.

Nesse contexto, destacamos as regiões de fronteiras como territórios onde essas dinâmicas se mostram ainda mais presentes e intensas, como é o caso da região fronteiriça do Brasil com a Guiana Francesa, onde o dispositivo ILM tem sido implementado para poder oferecer aos alunos falantes de português uma oportunidade de integração na escola francesa com o uso concomitante da língua portuguesa, bem como os elementos da cultura brasileira. Destacamos que, embora nos documentos oficiais do sistema de educação, não se fale expressamente em língua de herança, os pressupostos teórico-metodológicos e os objetivos expressos nos documentos analisados harmonizamse perfeitamente bem com aqueles relacionados ao ensino de língua de herança. Nesse diapasão, demonstramos, a partir de documentos de formação de professores do grupo de pesquisa encarregado pela avaliação e monitoramento do dispositivo ILM, que as principais dificuldades encontradas no ensino do português dizem respeito às fontes de consultas e materiais didáticos que sejam mais atrativos e mais adaptados aos alunos e ao contexto.

Vimos que a formação desses professores se baseia na própria legislação brasileira, que oferece normas gerais para o ensino do português no território nacional, ou seja, na Base Nacional Comum Curricular do Ministério da Educação do Brasil. No âmbito dessas formações, ficou registrado que há uma orientação para obtenção de material didático junto a sites oficiais 
Política linguística exterior brasileira e política linguística francesa em contato: o caso do português como língua de herança (PLH) no dispositivo Intervenant en Langue Maternelle na Guiana Francesa

do governo brasileiro e demais materiais disponibilizados na internet. Essa constatação demonstra claramente a importância de se produzir e aperfeiçoar um material de qualidade que sirva de referência para o ensino do português como língua de herança no exterior, a exemplo da Proposta curricular para o ensino de português como língua de herança (BRASIL, 2020b) do Ministério das Relações Exteriores.

Dessa forma, por todo o exposto neste artigo, procuramos demonstrar que o potencial de contribuição que um documento de referência, que sirva como parâmetro comum do ensino de PLH - como aqueles que já existem para a educação nacional - tem um potencial enorme para aperfeiçoamento, difusão e consolidação do PLH no mundo, quer seja no âmbito de associações privadas, redes de ensino consulares, ou mesmo, como no caso do presente artigo, em sistemas de ensino público de outros países.

\section{Referências}

ACADÉMIEDE GUYANE. Cadre réglementaire et didactique des habilitations à enseigner une/en L1. 2021 Disponível em: https://langues-de-guyane.ins.ac-guyane.fr/Habilitation-aenseigner-une-en-L1.html. Acesso em: 6 mar. 2021.

ACADÉMIE DE GUYANE. Carte des langues - portugais. 2020a. Disponível em: https://langues-de-guyane.ins.ac-guyane. fr/-Carte-des-langues-.html. Acesso em: 6 mar. 2021.

ACADÉMIE DE GUYANE. Carte des langues - portugais zone Est. 2020b. Disponível em: https://langues-de-guyane.ins. ac-guyane.fr/Carte-des-langues-le-portugais-zone-Est-Guyane. html. Acesso em: 6 mar. 2021. 
ACADÉMIE DE GUYANE. Circulaire sur le fonctionnement des classes de langues maternelles 2018. Lettre de cadrage du 18 juillet 2018a. Disponível em: https://langues-de-guyane. ins.ac-guyane.fr/Lettres-de-cadrage-et-ou-de-mission-des-ILM. html. Acesso em: 6 mar. 2021.

ACADÉMIE DE GUYANE. Compte rendu G.R.Ac (Groupe Recherche action) langues de l'est guyanais 2020: Bilan atelier portugais L1 du 2 \& 3 mars 2020 (Annexe 2). 2020c. Disponível em: https://langues-de-guyane.ins.ac-guyane.fr/GR-Ac-langues-de-l-est-guyanais-2020.html. Acesso em: 6 mar. 2021.

ACADÉMIE DE GUYANE. Le livret de l'Intervenant en Langue Maternelle (version décembre 2018). 2018 b. Disponível em: https://langues-de-guyane.ins.ac-guyane. fr/LE-LIVRET-DE-L-INTERVENANT-EN-LANGUEMATERNELLE.html. Acesso em: 6 mar. 2021.

ACADÉMIE DE GUYANE. Portal oficial da Education Prioritaire de Guyane 2020. 2020d. Disponível em: https:// educ-prioritaire.ins.ac-guyane.fr/IMG/pdf/00-flyer_ilm_2015150120.pdf. Acesso em: 6 mar. 2021.

ACADÉMIEDE GUYANE. Référentiel métier de l'intervenant en langue maternelle. 2019. Disponível em: https://languesde-guyane.ins.ac-guyane.fr/REFERENTIEL-METIER-DE-LINTERVENANT-EN-LANGUE-MATERNELLE.html. Acesso em: 6 mar. 2021.

ALVAREZ, Maria Luisa Ortiz; GONÇALVES, Luís. O mundo do Português e o Português no mundo afora: especificidades, implicações, ações. Campinas, SP: Editora Pontes, 2016. p. 201230.

BORUCHOWSKY, Ivian Destro. O que são falantes de herança? Como manter e desenvolver o português como língua de herança: sugestões para quem mora fora do Brasil. Miami: Must University, 2016. Cap. 2, p. 11-13. 
Política linguística exterior brasileira e política linguística francesa em contato: o caso do português como língua de herança (PLH) no dispositivo Intervenant en Langue Maternelle na Guiana Francesa

BRASIL. Ministério das Relações Exteriores. Portal consular: Guiana Francesa. Disponível em: http://www.portalconsular. itamaraty.gov.br/seu-destino/guiana-francesa\#comunidadebrasileira-e-principais-destinos. Acesso em: 6 mar. 2021.

BRASIL. Ministério das Relações Exteriores. Proposta curricular para o ensino de português como língua de herança. Brasília, 2020b. Disponível em: http://funag.gov. $\mathrm{br} / \mathrm{biblioteca} /$ index.php?route= product/product\&product $\mathrm{id}=1039$. Acesso em: 6 mar. 2021.

CONSEIL DE L'EUROPE. Cadre européen commun de reference: apprendre, enseigner, évaluer. Disponível em: https:// rm.coe.int/16802fc3a8. Acesso em: 6 mar. 2021.

FRANCE. Rapport à monsieur le directeur général de l'enseignement scolaire: évaluation des dispositifs favorisant la prise en compte des situations de plurilinguisme mis en place dans les académies d'Outre-mer et à Wallis-et-Futuna. 2020. Disponível em: https://www.education.gouv.fr/evaluation-desdispositifs-favorisant-la-prise-en-compte-des-situations-deplurilinguisme-dans-les-308428. Acesso em: 6 mar. 2021.

GARCÍA, Ofelia. Bilingual education in the 21st century: a global perspective. Oxford: Wiley-Blackwell, 2009.

LÉGLISE, Isabelle. Recherches guyanaises: langues parlées en Guyane. Repértoire linguistique, 2013. Disponível em: https:// www.vjf.cnrs.fr/sedyl/Isabelle_L\%C3\%A9glise/guyane/spip. php?article2\&lang=fr. Acesso em: 6 mar. 2021.

MENDES, Edleise. Vidas em Português: perspectivas culturais e identitárias em contexto de português língua de herança. Platô, [s. l.], v. 1, n. 2, p. 20-31, 2012.

MORINI, Andreia. O papel do progenitor não brasileiro na transmissão do PLH: suas práticas linguísticas e o impacto na proficiência dos filhos. Domínios da linguagem, Uberlândia, v. 12, n. 2, abr.-jun. 2018. 
RAJAGOPALAN, Kanavillil. Linguistics and the myth of nativity: comments on the controversy over "new/non-native Englishes". Journal of Pragmatics, [s. l.] v. 27, p. 225-231, 1997. SILVA, Karen Kênnia Couto. As políticas linguísticas do português na Guiana Francesa: quem planeja o quê, para quem e como? Tese (Doutorado em Linguística Aplicada) Universidade Federal de Minas Gerais, Belo Horizonte, 2020.

SILVA, Karen Kênnia Couto. O português como língua de herança na Guiana Francesa: entre realidades e potencialidades. Revista X, Curitiba, v. 13, n. 1, p. 297-322, 2018.

VALDÉS, Guadalupe. Bilingualism, heritage language learners and SLA research: opportunities lost or seized? The modern language journal, [s. l.], v. 89, n. 3, p. 410-426, 2005.

VALDÉS, Guadalupe. Introduction. Spanish for native speakers. AATSP professional development series handbook for teachers K-16, New York, v. 1, 2000.

VAN DEUSEN-SCHOLL, N. Towards a Definition of Heritage Language: Sociopolitical and Pedagogical Considerations. Journal of Language, Identity and Education, Nova York, v. 2, n. 3, 2003, p. 211-230.

YONAHA, Tabata Quintana; MUKAI, Yukinori. O português língua de herança (PLH) no contexto de emigrantes brasileiros no Japão: breve descrição das crenças e ações de mães brasileiras. 